\title{
Síndrome Complexa de Dor Regional do tipo I do membro superior: tratamento baseado no Estresse Muscular de Tração e Compressão Ativa
}

\author{
Aline Sarturi Ponte ${ }^{a}$, Barbara Santos Luccas Duarte ${ }^{\mathrm{b}}$, Maria Celoni de Mello de Godoyc, \\ Miriam Cabrera Corvelo Delboni ${ }^{\mathrm{b}}$, Thais Rosa Costa ${ }^{\mathrm{b}}$
}

aPrograma de Pós-graduação em Distúrbios da Comunicação Humana, Universidade Federal de Santa Maria - UFSM, Santa Maria, RS, Brasil

${ }^{\text {b} C u r s o ~ d e ~ T e r a p i a ~ O c u p a c i o n a l, ~ U n i v e r s i d a d e ~ F e d e r a l ~ d e ~ S a n t a ~ M a r i a ~-~ U F S M, ~ S a n t a ~ M a r i a, ~ R S, ~ B r a s i l ~}$

${ }^{c}$ Curso de Medicina, Universidade Federal de Santa Maria - UFSM, Santa Maria, RS, Brasil

\begin{abstract}
Resumo: O cotidiano de uma pessoa que sofre de Síndrome Complexa de Dor Regional de tipo I (SCDR I) passa a ser limitado, pois essa síndrome gera sinais e sintomas localizados no membro acometido, podendo também se estabelecer em outros locais. Tendo isso em vista, este estudo objetiva apresentar as contribuições da Terapia Ocupacional e do Programa de Reabilitação Baseado no Estresse Muscular de Tração e Compressão Ativa para um sujeito com SCDR I no membro superior, atendido pelo Grupo de Dor do Hospital Universitário de Santa Maria (HUSM), RS. A presente pesquisa é caracterizada como um estudo de caso, experimental, que se ocupa dos períodos pré e pós-intervenção terapêutica ocupacional. Os instrumentos utilizados para coleta de dados foram os protocolos de Disfunção Ombro, Braço, Mão (DASH), a Classificação Internacional de Incapacidade, Funcionalidade e Saúde (CIF), a Medida Canadense de Desempenho Ocupacional (COPM), a Goniometria e a Escala Visual Analógica (EVA). Findas as avaliações, o sujeito foi exposto ao tratamento de exercícios ativos resistivos compressivos e, após a conclusão do tratamento, foi reavaliado. Observou-se, então, que o tratamento aplicado contribuiu para a diminuição do quadro doloroso e para a melhoria na Amplitude de Movimento (ADM) do sujeito. A utilização do protocolo de estresse e compressão ativa contribuiu significativamente para a redução da dor, o ganho de ADM e a melhora do desempenho ocupacional.
\end{abstract}

Palavras-chave: Dor Crônica, Terapia Ocupacional, Avaliação, Funcionalidade.

\section{Complex Regional Pain Syndrome type I of the upper limb - treatment based on Stress Loading Program: a case study}

\begin{abstract}
The daily life of an individual suffering from Complex Regional Pain Syndrome type I (CPRS I) becomes limited, because this syndrome causes signs and symptoms located in the affected limb, and may occur in other parts. From this premise, this study aims to present the contributions of Occupational Therapy and the Rehabilitation Stress Loading Program for a subject with CRPS I in the upper limb, attended by the Group of Pain from the University Hospital of Santa Maria (HUSM), Rio Grande do Sul state. This research is characterized as a case study, experimental, which deals with pre and post occupational therapy intervention. The instruments used for data collection were the protocols of Disabilities of the Arm, Shoulder and Hand (DASH), the International Classification of Disability, Functioning and Health (ICF), the Canadian Occupational Performance Measure (COPM), the Visual Analogue Scale, and goniometry (EVA). After assessment, the subject was exposed to the treatment of compressive active resistive exercises; after this treatment was completed, the subject was reassessed.
\end{abstract}

Autor para correspondência: Aline Sarturi Ponte, Av. Roraima, 1000, prédio 26, sala 1306, Campus UFSM, Bairro Camobi, CEP 97015-900, Santa Maria, RS, Brasil, e-mail: alinesarturi@hotmail.com

Recebido em Set. 30, 2013; Revisão em Maio 1, 2014; Aceito em Maio 19, 2014. 
It was observed that the treatment applied has contributed to the reduction of the pain and to the improvement in the Range of Motion (ROM) of the subject. The use of the stress protocol and active compression contributed significantly to the reduction of pain, ADM gain and occupational performance improvement.

Keywords: Chronic Pain, Occupational Therapy, Evaluation, Functionality.

\section{Introdução}

Os membros superiores (MMSS)

[...] são poderosas ferramentas do ser humano, o que sinaliza a importância desse segmento e representação na constituição e função do Sistema Nervoso Central (SNC) [...]" (DAAMEN-DEZOTTI; FERRIGNO; CRUZ, 2011, p. 1).

Dois quartos da superfície córtico-cerebral (homúnculo de Penfield) são representados pela função motora e sensitiva da mão, principalmente do indicador e polegar (FONSECA, 1998; SALTER; CHEEHIRE, 2000; FERRIGNO, 2007).

Ao atingir o MMSS, a dor, além de gerar estresses físicos, emocionais e perdas para os sujeitos e seus cuidadores, causa fardo econômico para a sociedade, pois torna-se importante ônus para serviços médicos, institutos de previdência e companhias de seguro (TEIXEIRA et al., 2001). Sabe-se que um dos principais motivos que leva a população a procurar o auxílio dos serviços de saúde é a dor. A dor

[...] é um processo natural, essencial à sobrevivência, um mecanismo de alerta que indica ao organismo a presença de dano tecidual para que esse reaja ativando os mecanismos de defesa, visando garantir sua proteção [...] (FUCHS; CASSAPIAN, 2012, p. 108).

A Síndrome Complexa de Dor Regional de tipo I (SCDR I) caracteriza-se por uma dor intensa que acomete uma extremidade do corpo. Em 1994, a Associaçáo Internacional para o Estudo da Dor (IASP), diante dos numerosos nomes para essa síndrome (Distrofia Simpático Reflexa, Causalgia, Algodistrofia ou Atrofia de Sudeck) estabeleceu critérios para seu diagnóstico e a classificou como síndrome, definindo dois tipos: SCDR tipo I) Conhecida como síndrome de distrofia simpático reflexa (DSR). Sucede a uma doença ou lesão que não afetou diretamente os nervos no membro afetado. Em torno de $90 \%$ das pessoas com SCDR sofrem do tipo I. SCDR tipo II). Conhecida como causalgia, esse tipo sucede lesões distintas aos nervos (ARAÚJO; NEVES, 2007).
A etiologia da SCDR encontra-se ainda indefinida (LAURETTI; VELOSO; MATTOS, 2005). A incidência dessa síndrome é maior no sexo feminino, a partir da quarta década de vida, em apenas um membro, sendo que 57\% delas desenvolvem-se no primeiro mês após a lesão. Amatuzzi (2004) relata ser mais comum nos membros superiores, porém Choi, Lee e Lee (2008) descreveram maior incidência nos membros inferiores.

A SCDR I caracteriza-se por sinais e sintomas sensitivos, neurovegetativos e motores. A dor é definida pelo sujeito acometido como queimaçáo, latejamento ou peso na região comprometida, bem como dor intensa e espontânea e hiperalgesia. $\mathrm{O}$ sujeito que tem essa patologia pode apresentar alguns sintomas motores, como espasmos musculares, limitação na amplitude de movimento, tremores, déficit de força, distonia, edema, mudança na temperatura e coloração da pele. Alteraçóes tróficas como retração tendínea e ligamentar e amiotrofia podem ocorrer na fase crônica. Os movimentos finos, como preensão e função de pinça, comumente estaráo comprometidos nesses pacientes (ZAKKA et al., 2011).

O tratamento mais utilizado é o bloqueio do sistema nervoso neurovegetativo simpático, além disso indica-se o tratamento farmacológico, bloqueios anestésicos, terapia psíquica e comportamental, programa de educaçẫo cognitivocomportamental em dor crônica, neurocirúrgico funcional, neurólise, descompressão, tratamento fisioterapêutico e terapêutico ocupacional. Diante da complexidade que acomete o sujeito com SCDR, observa-se a necessidade de uma atenção multidisciplinar (AMATUZZI, 2004).

Tendo em vista as desordens temporárias ou crônicas causadas pela patologia e o grande impacto dela nas atividades cotidianas, o terapeuta ocupacional deve considerar os aspectos emocionais, psicológicos e sociais do sujeito acometido. Segundo Ferrigno (2007), o terapeuta ocupacional precisa levar em conta os fatores de estresse causados pelo trauma no sujeito.

O objetivo deste estudo, nesse contexto, foi apresentar as contribuiçôes da Terapia Ocupacional e do Programa de Reabilitaçáo Baseado no Estresse Muscular de Tração e Compressão Ativa para um 
sujeito com SCDR I no Membro Superior, tratado pelo Grupo de Dor do Hospital Universitário de Santa Maria (HUSM), RS.

\section{Metodologia}

Este estudo iniciou após ser aprovado pelo Comitê de Ética em Pesquisa em Seres Humanos da Universidade Federal de Santa Maria (UFSM), RS, número do parecer: 206.175. É caracterizado com um estudo de caso, experimental, que trata dos períodos pré e pós-intervenção terapêutica ocupacional, em que o sujeito foi submetido a dez semanas de intervenção terapêutica ocupacional, das quais duas foram destinadas às avaliaçóes iniciais e finais e oito à intervenção com o programa de tratamento escolhido e coleta de dados. A terapia presencial foi composta por uma sessão semanal, com duração de uma hora, dividida em três momentos: o primeiro momento era mediado por uma conversa, na qual a pesquisadora colhia dados referentes à realizaçáo dos exercícios no decorrer da semana; no segundo avaliava-se o ângulo articular do membro acometido pela síndrome, com intuito de averiguar se o participante estava realmente realizando os exercícios em seu domicílio; e no terceiro momento ocorria a aplicação da intervenção. Além das intervençôes terapêuticas presenciais, o participante foi orientado a realizar o exercício três vezes ao dia, todos os dias da semana, na sua residência.

Os protocolos utilizados para a coleta de dados de interesse da pesquisa foram: a Classificação Internacional de Funcionalidade, Incapacidade e Saúde (CIF), a Disfunção Ombro, Braço e Mão (DASH), a Medida Canadense de Desempenho Ocupacional (COPM), a Goniometria e a Escala Visual Analógica (EVA).

A CIF proporciona uma descrição de situações relacionadas às funções humanas e às suas restriçôes, além de uma linguagem comum aos usuários e profissionais da saúde (SAMPAIO et al., 2005). Foi realizada uma entrevista guiada pela CIF, onde o paciente respondia sobre as barreiras encontradas em seu cotidiano em virtude da doença, visando as limitaçôes de estruturas e função corporal, atividade, participação e fatores pessoais e ambientais.

O método DASH foi adaptado para o português em 2003 e é um instrumento de avaliação usado para medir sintomas e função no membro superior (DRUMOND, 2006).
É um instrumento que avalia função e sintomas no membro superior sob a perspectiva do paciente. Trata-se de um instrumento que, independente da afecção ou de sua localização, avalia o membro superior enquanto uma unidade funcional [...] (CHENG, 2006, p. 7).

Essa avaliação é dividida em três partes: a primeira refere-se às atividades de vida diária (AVDs) e atividades instrumentais de vida diária (AIVDs); a segunda, à atividade de prática esportiva e musical; e a terceira, às atividades de trabalho. No presente estudo não foi utilizada a segunda parte do questionário pertencente ao método em questão devido ao sujeito não desenvolver as atividades abordadas.

A COPM é uma avaliação centrada nas perspectivas do sujeito, em que ele identifica os principais problemas em seu cotidiano e pontua o desempenho e a satisfação em relação às AVDs e AIVDs (ANDOLFATO; MARIOTTI, 2009). A COPM baseia-se na autopercepção do sujeito em relação ao seu desempenho ocupacional na vida diária nas áreas de autocuidado, produtividade e lazer e visa identificar em quais áreas os sujeitos apresentam problemas, quantificar as prioridades, analisar o desempenho e a satisfação diante dos problemas encontrados e mensurar as mudanças apresentadas pelo sujeito durante a intervenção terapêutica ocupacional (MAGALHÃES; MAGALHĀES; CARDOSO, 2009). Por meio da COPM, o participante selecionou as atividades que ele não estava conseguindo realizar ou nas quais não estava satisfeito com seu desempenho durante a execução. Essas atividades englobam em qualquer uma das áreas de desempenho: autocuidado, trabalho e lazer. Na primeira fase da avaliação, o participante atribui à atividade selecionada uma importância, a pontuação varia de 1 (não é importante) a 10 (extremamente importante). $\mathrm{Na}$ segunda fase da avalição, o participante seleciona cinco atividades das citadas anteriormente, as quais considerou mais importantes, foram elas: lavar o rosto, cortar carne, trabalho agrícola, preparar refeiçóes e pescar, e a essas atribuiu uma pontuação, também numa escala de 1 (não é capaz de desempenhar) a 10 (capaz de desempenhar muito bem), em relação ao desempenho nessas atividades e à satisfação com esse desempenho: 1 (não satisfeito de forma nenhuma) e 10 (extremamente satisfeito) (MAGALHÃES; MAGALHÃES; CARDOSO, 2009).

Já a Goniometria é um método cinemático de mensuração dos ângulos articulares de um corpo, amplamente utilizado por diversos profissionais 
da saúde. Essa é uma ferramenta de mensuração objetiva e deve fazer parte do exame ortopédico (CURY et al., 2006). As articulaçôes avaliadas no estudo foram ombro, cotovelo, punho e mão: solicitou-se ao sujeito que realizasse os movimentos de forma ativa. Para a coleta de dados o sujeito permaneceu sentado. Para mensuração foram usados dois goniômetros, um goniômetro universal marca Fisiomed Brasil e um goniômetro de dedos na mesma marca.

A EVA é utilizada para mensurar quantitativamente a dor, podendo detectar pequenas diferenças no que diz respeito à intensidade. Essa escala compreende uma linha horizontal que apresenta valores de 0 (ausência de dor) a 10 (a pior dor possível). $\mathrm{Na}$ sua utilizaçáo pede-se para o sujeito marcar na linha o local que melhor representa a intensidade da sua dor; após, utiliza-se uma régua para numerar a marca realizada pelo paciente, obtendo-se, assim, um equivalente numérico para a dor (MRUS et al., 2003).

Como método de tratamento de síndromes neuropáticas como a SCDR I, Watson (1987) criou o programa de tratamento de reabilitaçáo baseado no estresse muscular de traçáo e compressáo ativa. O método utiliza exercícios ativos resistivos compressivos e requer o uso estressante da extremidade superior com movimento articular mínimo (CORVELO et al., 1997; MORRIN; DAVEY; CONOLLY, 2001; FREITAS, 2006).

O Programa de Reabilitação Baseado no Estresse Muscular de Tração e Compressão Ativa é uma técnica utilizada para reabilitação de sujeitos acometidos pela SCDR. Os exercícios constituintes desse programa devem ser realizados de maneira suave e lenta, porque se realizados vigorosamente podem causar mais dor, edema e rigidez. Para um melhor desempenho nas atividades deve-se incluir o membro não acometido pela síndrome. Esse programa pode ser orientado pelo terapeuta ocupacional, que ensina e estimula o paciente a continuar realizando os exercícios em casa, várias vezes ao dia, de maneira sistemática e contínua (MULLINS, 1992; WALSH, 1995; DZWIERZYNSKI; SANGER, 1994; FONSECA, 1995; FREITAS, 2000; GALER; DWORKIN, 2001; ARAÚJO et al., 2007).

Esse programa divide-se em dois momentos: no ato de esfregar e de carregar. No ato de esfregar o sujeito posicionava-se em pé e apoiava-se a uma superfície e, com o membro acometido, realizava movimento de flexão e extensão com o ombro - cotovelo e punho permanecem em extensão e os dedos, flexionados. O exercício é realizado visando o mínimo de movimentação articular. $\mathrm{O}$ sujeito aplica uma preensão máxima sobre a superfície; para execução do movimento utiliza-se o Dystrophile, caso o sujeito náo consiga realizar o movimento com o aparelho pode-se utilizar materiais alternativos (toalha, escovas de esfregar roupa com cerdas grossas). Graduando-se o tempo, inicia-se com três minutos, aumentando-se para seis minutos, até se alcançar oito minutos. No ato de carregar, o sujeito, com o membro superior em extensão, deve segurar uma sacola, em movimento ou parado, contendo o máximo de peso que o indivíduo consiga suportar. Esse exercício deve ser realizado três vezes ao dia. $\mathrm{O}$ ato de carregar deve vir na sequência do ato de esfregar (CORVELO et al., 1997; MORRIN; DAVEY; CONOLLY, 2001; FREITAS, 2006).

Esse método de tratamento conta com um aparelho, o Dystrophile, o qual apresenta uma mola de carga graduada em 2 k, 4 k e 6 k e conta, ainda, com um timer, que registra o tempo que o paciente permanece realizando o exercício de forma correta. Para a realizaçáo desse exercício, o participante, posicionado em pé, deve pressionar o Dystrophile com o membro acometido, deslocando-o para frente e para trás e mantendo a pressão; o timer marcará, então, o tempo de duração do exercício (CORVELO et al., 1997; MORRIN; DAVEY; CONOLLY, 2001; FREITAS, 2006).

Corvelo (1997) realizou um estudo baseado em Watson (1987) no qual aplicou esse tratamento em 25 sujeitos, obtendo resultados satisfatórios em 23 deles. Esse modelo de tratamento se utiliza do ato de esfregar e carregar, provocando uma vasodilatação reflexa e inibição do ciclo vasoconstritor característico da SCDR I.

\section{Resultados}

O participante do estudo é do sexo masculino, 59 anos, casado, agricultor, mas no momento encontrava-se afastado das atividades de trabalho e recebia auxílio-doença do Instituto Nacional do Seguro Social (INSS). Há dois anos, no trajeto entre sua residência e o local de trabalho, foi atropelado e fraturou o membro superior esquerdo na porção distal do úmero.

O paciente recebeu os primeiros socorros em sua cidade, Paraíso do Sul, RS, e foi encaminhado para Santa Maria, RS, para realizaçâo de cirurgia. Após receber alta, retornou a sua cidade e iniciou o tratamento fisioterápico, o qual seguia realizando. Com o passar do tempo, procurou o médico 
novamente, com queixas de dores constantes no membro fraturado. Após diversos exames e medicaçôes que náo amenizaram os sintomas e com a intensificaçáo do quadro de dor e o afastamento das atividades de trabalho, o sujeito foi encaminhado para o Grupo de Dor do Hospital Universitário de Santa Maria (HUSM), onde foi diagnosticado com SCDR I e onde permaneceu em acompanhamento mensal para atendimentos médicos e realização de bloqueios químicos. Foi encaminhado ao Serviço de Terapia Ocupacional através de um projeto de pesquisa intitulado Dor Neuropática nos Membros Superiores: Capacidade Funcional e Aspectos Sociais. À época da pesquisa encontrava-se em atendimento fisioterápico e terapêutico ocupacional.

Após a apresentação do projeto ao sujeito e seu aceite de participação por meio da assinatura do Termo de Consentimento Livre e Esclarecido, deu-se início à intervençáo terapêutica. Realizou-se, ainda, uma breve explicaçáo sobre a patologia e sobre o método de intervenção proposto pelo projeto. $\mathrm{Na}$ segunda sessão, deu-se início ao Programa de Reabilitação Baseado no Estresse Muscular de Tração e Compressão Ativa. O programa de tratamento inicia-se pelo ato de esfregar. Para tanto, utilizou-se de uma toalha como base para o apoio, pois o sujeito não conseguiu realizar a atividade com o aparelho Dystrophile devido à diminuição da força causada pelo desuso do membro afetado.

Ao utilizar um material alternativo para a realização do programa, o sujeito deve contar o número de vezes que consegue realizar o ato de esfregar e utilizar esse número como base de tempo para o ato de carregar. O exercício de esfregar foi realizado três vezes e, após ter atingido um número de repetiçóes, o paciente náo pode retroceder. No primeiro contato do sujeito com o programa, ele realizou o exercício três vezes, intercalando os atos de esfregar e carregar. No decorrer das intervençóes observou-se um grande empenho do participante, a partir de seus relatos e das mensuraçóes goniométricas observavam-se as contribuiçóes do tratamento. Nas primeiras intervenções, as queixas eram relacionadas a dor e às dificuldades enfrentadas nas tarefas cotidianas. Ao longo das semanas, essas queixas foram anemizando-se, a dor persistia, mas agora era mais amena, as limitaçóes também continuavam mas, com a diminuição da sensação dolorosa, a realização das tarefas cotidianas passou a ser menos penosa.

O sujeito participante deste estudo tinha os movimentos limitados nos $1^{\circ}, 2^{\circ}, 3^{\circ}, 4^{\circ}$ e $5^{\circ}$ quirodáctilos e, consequentemente, apresentava dificuldades de realizar atividades do cotidiano, como alimentação, autocuidado, higiene, trabalho, entre outras. Com a intensidade da dor, o sujeito passa a proteger o membro acometido, evitando assim envolvê-lo em suas AVDs e AIVDs por medo de sentir dor, e essa negligência gera sequelas que incluem diminuição da preensáo palmar e do movimento de pinça, atrofia muscular, rigidez articular e, por conseguinte, diminuição da amplitude de movimento (ADM).

Observou-se que além de auxiliar na redução do quadro doloroso esse tratamento contribuiu para a restauração da $\mathrm{ADM}$ das grandes e pequenas articulaçóes, como se apresenta na Tabela 1 . Apesar da ADM não estar completa, os ganhos foram significativos, o que permitiu que o participante alcançasse êxito na realizaçáo das AVDs e AIVDs.

A avaliação da intensidade da dor, neste estudo, foi feita utilizando-se a EVA, tendo o sujeito referido nota dez para o nível de dor na primeira avaliação, o que corresponde a um nível insuportável do quadro doloroso. Já ao ser reavaliado, o paciente referiu nota cinco para a dor que sentia, o que denota uma diminuição do quadro doloroso.

Diante dessa melhora, o sujeito tende a retomar suas atividades diárias, como pode ser observado na COPM, em que o sujeito afirmou ter se envolvido mais nas atividades diárias, melhorando o seu desempenho ocupacional e a sua satisfação diante das atividades realizadas, como pode ser visto na Tabela 2, que apresenta a avaliaçáo do desempenho ocupacional antes e após as intervençóes.

$\mathrm{Na}$ avaliação da COPM apresenta-se um item em que a pessoa avalia o seu desempenho e satisfaçáo diante de suas atividades de lazer. Ao ser questionado sobre suas atividades de lazer, o participante não mencionou nenhuma atividade, deixando esse item em branco.

O DASH é um instrumento que visa à avaliação dos membros superiores (ombro, braço e mão), os quais são parte extremamente importante do corpo humano para a realização das AVDs. Em sua primeira parte, o DASH apresenta questóes referentes às AVDs (autocuidado, mobilidade, alimentação, higiene pessoal, bem como os atos de vestir, despir, calçar) e às AIVDs (ir às compras, gerir o dinheiro, utilizar o telefone, limpar, cozinhar, utilizar transportes).

$\mathrm{Na}$ Tabela 3 observa-se que na avaliação o sujeito referiu que houve dificuldade média (46,60\%) na realização de suas AVDs e AIVDs nas últimas semanas, já na reavaliação observa-se uma alteração nesses valores, o sujeito menciona 
Tabela 1. Avaliação goniométrica.

\begin{tabular}{|c|c|c|}
\hline Avaliação & Articulação a ser avaliada & Reavaliação \\
\hline Data: $8 / 3 / 2013$ & OMBRO & Data: $7 / 5 / 2013$ \\
\hline $60^{\circ}$ & Flexão & $120^{\circ}$ \\
\hline $40^{\circ}$ & Extensão & $48^{\circ}$ \\
\hline $90^{\circ}$ & Abdução & $100^{\circ}$ \\
\hline $80^{\circ}$ & Abdução horizontal & $90^{\circ}$ \\
\hline $40^{\circ}$ & Adução horizontal & $30^{\circ}$ \\
\hline $40^{\circ}$ & Rotação interna & $50^{\circ}$ \\
\hline \multirow[t]{2}{*}{$50^{\circ}$} & Rotação externa & $70^{\circ}$ \\
\hline & COTOVELO E ANTEBRAÇO & \\
\hline $60^{\circ}$ & Extensão & $120^{\circ}$ \\
\hline $0^{\circ}$ & Flexão & $0^{\circ}$ \\
\hline $80^{\circ}$ & Supinação & $80^{\circ}$ \\
\hline \multirow[t]{2}{*}{$80^{\circ}$} & Pronação & $80^{\circ}$ \\
\hline & PUNHO & \\
\hline $35^{\circ}$ & Flexão & $40^{\circ}$ \\
\hline $10^{\circ}$ & Extensão & $20^{\circ}$ \\
\hline $20^{\circ}$ & Desvio ulnar & $20^{\circ}$ \\
\hline \multirow[t]{2}{*}{$10^{\circ}$} & Desvio radial & $20^{\circ}$ \\
\hline & PRIMEIRO DEDO & \\
\hline $7^{\circ}$ & Flexão CM & $9^{\circ}$ \\
\hline $6^{\circ}$ & Extensão CM & $9^{\circ}$ \\
\hline $15^{\circ}$ & Flexão de MF & $29^{\circ}$ \\
\hline $10^{\circ}$ & Extensão de IF & $70^{\circ}$ \\
\hline \multirow[t]{2}{*}{$0^{\circ}$} & Flexão & $0^{\circ}$ \\
\hline & SEGUNDO DEDO & \\
\hline $45^{\circ}$ & Flexão de MF & $55^{\circ}$ \\
\hline $0^{\circ}$ & Extensão de IFP & $0^{\circ}$ \\
\hline $20^{\circ}$ & Flexão IFP & $25^{\circ}$ \\
\hline $0^{\circ}$ & Extensão de IFD & $0^{\circ}$ \\
\hline \multirow[t]{2}{*}{$30^{\circ}$} & Flexão IFD & $50^{\circ}$ \\
\hline & TERCEIRO DEDO & \\
\hline $40^{\circ}$ & Flexão de MF & $55^{\circ}$ \\
\hline $0^{\circ}$ & Extensão de IFP & $0^{\circ}$ \\
\hline $30^{\circ}$ & Flexão IFP & $33^{\circ}$ \\
\hline $0^{\circ}$ & Extensão IFD & $0^{\circ}$ \\
\hline \multirow[t]{2}{*}{$40^{\circ}$} & Flexão IFD & $41^{\circ}$ \\
\hline & QUARTO DEDO & \\
\hline $55^{\circ}$ & Flexão de MF & $60^{\circ}$ \\
\hline $0^{\circ}$ & Extensão de IFP & $0^{\circ}$ \\
\hline $35^{\circ}$ & Flexão IFP & $40^{\circ}$ \\
\hline $0^{\circ}$ & Extensão de IFD & $0^{\circ}$ \\
\hline \multirow[t]{2}{*}{$40^{\circ}$} & Flexão IFD & $40^{\circ}$ \\
\hline & QUINTO DEDO & \\
\hline $55^{\circ}$ & Flexão de MF & $50^{\circ}$ \\
\hline $0^{\circ}$ & Extensão de IFP & $0^{\circ}$ \\
\hline $60^{\circ}$ & Flexão IFP & $64^{\circ}$ \\
\hline $0^{\circ}$ & Extensão de IFD & $0^{\circ}$ \\
\hline $50^{\circ}$ & Flexão IFD & $50^{\circ}$ \\
\hline
\end{tabular}

CM: carpometacarpal; MF: metacarpo falangeana; IFP: interfalangeana proximal; IFD: interfalangeana distal. 
uma diminuição nas dificuldades, ou seja, não houve dificuldades $(46,60 \%)$ na realização de suas atividades cotidianas.

As questôes abordadas referem-se às dificuldades encontradas na execução de atividade laboral, considerando a técnica habitual utilizada na execução da tarefa, a dor no MMSS e sua interferência na atividade laboral, o quanto está satisfeito com o resultado do seu trabalho e com o tempo que utiliza para desempenhá-lo.

Como observa-se na Tabela 4, as habilidades de trabalho do participante do estudo estavam limitadas devido às dores intensas que o impossibilitavam de realizá-las. $\mathrm{Na}$ avaliação, o participante considerou o ato de executar a sua atividade de trabalho como muito difícil (75\%) e não conseguiu realizá-la (25\%). Já na reavaliação, o participante apresentou uma dificuldade média $(50 \%)$, continuou a considerar algumas atividades muito difíceis (25\%) e permaneceu náo conseguindo realizar a sua atividade laboral (25\%).

A adoção da CIF possibilita ao terapeuta ocupacional, em seus procedimentos de avaliação e de intervenção, considerar um perfil funcional específico para cada indivíduo. Na Tabela 5 estấo descritos os resultados da CIF a partir de seus qualificadores. Ele apresenta as limitaçóes de estruturas e funçáo corporal, atividade, participação e fatores pessoais e ambientais coletadas neste estudo.

Ao discutir as estruturas e funçóes corporais o participante apresentou diversas limitaçóes. Após a realização do programa de tratamento de reabilitação baseado no estresse muscular de tração e compressão ativa, observou-se melhora nas seguintes estruturas: dor, mobilidade, força muscular, medula espinhal e nervos periféricos, região do ombro e extremidade superior. Essa melhora repercutiu na execução das atividades de levantar e carregar objetos, dirigir, lava-se, cuidar das partes do corpo e vestir-se - no aspecto participação o sujeito demostrou melhora nas atividades de trabalho. Os fatores ambientais e pessoais não sofreram alteraçóes durante o tratamento.

O programa de tratamento de reabilitação baseado no estresse muscular de tração e compressáo ativa contribuiu para significativa diminuição do quadro álgico, como demonstrado pela EVA, atingindo assim o objetivo principal do programa.

Tabela 2. Medida canadense de desempenho ocupacional (COPM).

\begin{tabular}{|c|c|c|c|c|c|}
\hline $\begin{array}{c}\text { Áreas de } \\
\text { desempenho } \\
\text { ocupacional }\end{array}$ & $\begin{array}{l}\text { Problemas de } \\
\text { desempenho } \\
\text { ocupacional }\end{array}$ & $\begin{array}{c}\text { Avaliação } \\
8 / 3 / 2013\end{array}$ & $\begin{array}{l}\text { Avaliação } \\
8 / 3 / 2013\end{array}$ & $\begin{array}{c}\text { Reavaliação } \\
7 / 5 / 2013\end{array}$ & $\begin{array}{c}\text { Reavaliação } \\
7 / 5 / 2013\end{array}$ \\
\hline & & Desempenho 1 & Satisfação 1 & Desempenho 2 & Satisfação 2 \\
\hline \multirow[t]{2}{*}{ Autocuidado } & Lavar o rosto & 3 & 5 & 9 & 10 \\
\hline & Cortar carne & 3 & 3 & 6 & 8 \\
\hline \multirow[t]{3}{*}{ Produtividade } & $\begin{array}{l}\text { Trabalho } \\
\text { agrícola }\end{array}$ & 0 & 0 & 2 & 4 \\
\hline & $\begin{array}{l}\text { Preparo das } \\
\text { refeições }\end{array}$ & 6 & 8 & 8 & 9 \\
\hline & Pescar & 7 & 8 & 9 & 9 \\
\hline
\end{tabular}

Tabela 3. DASH - Questões direcionadas a Atividades de Vida Diária.

\begin{tabular}{lccccc}
\hline & $\begin{array}{c}\text { Não houve } \\
\text { dificuldade }\end{array}$ & $\begin{array}{c}\text { Houve pouca } \\
\text { dificuldade }\end{array}$ & $\begin{array}{c}\text { Houve dificuldade } \\
\text { média }\end{array}$ & $\begin{array}{c}\text { Houve muita } \\
\text { dificuldade }\end{array}$ & $\begin{array}{c}\text { Não conseguiu } \\
\text { fazer }\end{array}$ \\
\hline Avaliação & $10,00 \%$ & $6,60 \%$ & $46,60 \%$ & $23,30 \%$ & $13,30 \%$ \\
Reavaliação & $46,60 \%$ & $33,30 \%$ & $26,60 \%$ & $6,60 \%$ & $3,30 \%$ \\
\hline
\end{tabular}

Tabela 4. DASH - Questões direcionadas às atividades de trabalho.

\begin{tabular}{l|ccccc}
\hline & Fácil & Pouco difícil & $\begin{array}{c}\text { Dificuldade } \\
\text { média }\end{array}$ & $\begin{array}{c}\text { Muito difícil } \\
\text { Não conseguiu } \\
\text { fazer }\end{array}$ \\
\hline Avaliação & $0 \%$ & $0 \%$ & $0 \%$ & $75 \%$ & $25 \%$ \\
Reavaliação & $0 \%$ & $0 \%$ & $50 \%$ & $25 \%$ & $25 \%$ \\
\hline
\end{tabular}




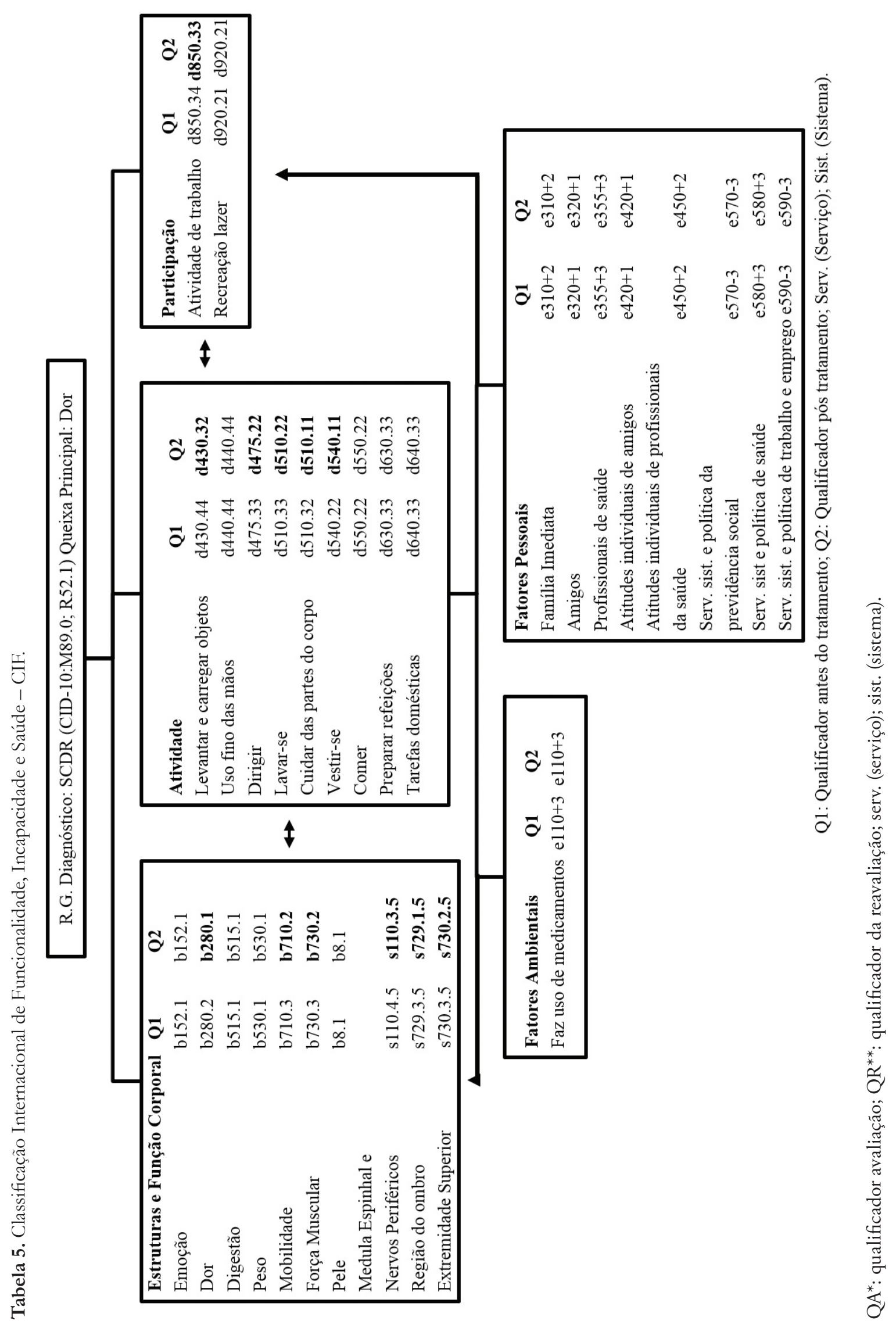


A partir das demais avaliaçóes (goniometria, CIF, COPM, DASH) observou-se que o sujeito obteve outros benefícios com o programa. São eles: o ganho de ADM, força muscular, mobilidade, melhora nas AVDs, nas AIVDs e nas atividades laborais e, consequentemente, melhora no desempenho ocupacional e na qualidade de vida do sujeito acometido por SCDR I.

\section{Discussões}

O sujeito tende a adquirir posturas de proteção, pois é um meio utilizado para amenizar a dor, porém essa nova postura adotada poderá comprometer outras estruturas musculoesqueléticas envolvidas no seguimento (FONSECA et al., 2006; FUCHS; CASSAPIAN, 2012).

Portanto, o terapeuta ocupacional deve orientar o sujeito quanto às posturas durante a realizaçáo de suas atividades cotidianas - sentadas ou em pé [...] (FUCHS; CASSAPIAN, 2012, p. 116).

A atuação do terapeuta ocupacional com pacientes acometidos pela SCDR I não se limita apenas a buscar uma melhoria funcional do membro afetado. Inclui a promoção da autonomia e independência do indivíduo, procurando, assim, proporcionar também a melhoria do desempenho ocupacional e da condiçấo emocional do paciente.

Portanto, para atingir os seus objetivos junto ao sujeito com SCDR I, o terapeuta ocupacional deve utilizar-se de diversos métodos de tratamento, tais como terapia da mão, treino de AVDs, tecnologia assistiva, simplificação de tarefa, orientaçôes, educação e controle do estresse, biofeedback, intervençóes comportamentais, treino de técnicas de relaxamento, órteses, atividades de lazer individual e grupal, treino de tolerância ao trabalho, conservação de energia, proteção articular, ergonomia (FUCHS; CASSAPIAN, 2012).

Essas formas são as mais utilizadas junto a pessoas com essa síndrome, já o programa de tratamento de reabilitaçáo baseado no estresse muscular de tração e compressão ativa é um método de tratamento pouco explorado. $\mathrm{O}$ programa estimula a mobilização ativa articular, pois tal mobilização auxilia no fluxo sanguíneo, contribuindo para uma melhora na oxigenação da musculatura acometida pela síndrome. Além disso, os exercícios ativos suavizam os impulsos de dor, à medida que excitam as fibras aferentes de grande diâmetro ou estimulam a liberação de opioides endógenos. Também são efetivos no controle do edema, da rigidez articular e da contratura muscular (ARAÚJO; NEVES, 2007).

Os sujeitos com SCDR I têm características peculiares e necessidades abrangentes, que envolvem autocuidado, produtividade e de lazer. Embora tais atividades façam parte da vida de qualquer ser humano, os sujeitos acometidos por essa patologia apresentam maior dificuldade para realizá-las. As consequências da SCDR I no cotidiano do sujeito são drásticas, incluindo limitaçôes nas AVDs, nas AIVDs e nas atividades produtivas, o que resulta em um sofrimento persistente provocado pela dor (ROCHA, 2011).

\section{Considerações finais}

A dor é um sinal de alerta de que algo não está bem no organismo. Mas quando a dor se transforma em uma dor crônica e acaba influenciando o cotidiano do sujeito, as intervençôes terapêuticas ocupacionais devem buscar estimular a promoção da independência nas atividades da vida diária e laborais do paciente acometido por essa patologia.

O terapeuta ocupacional é um agente facilitador dessas atividades cotidianas, pois planeja estratégias visando à autonomia e independência do seu paciente e que acabam por melhorar a qualidade de vida dele. A intervenção terapêutica ocupacional deve objetivar, portanto, a exploração dos potenciais remanescentes e a melhora da qualidade de vida desses sujeitos.

O profissional que trabalha com sujeitos que sofrem de dor crônica deve considerar esses sujeitos em todo o seu contexto, ou seja, social, psicológico e funcional. Sabe-se que esse afastamento causa vários danos na vida do sujeito, afetando seu cotidiano. Poucas pesquisas são realizadas nesse contexto e ainda há muito a ser feito.

Neste estudo, pôde-se observar que os instrumentos utilizados nas avaliaçóes contribuíram para a compreensão dos vários aspectos que envolvem o cotidiano de pessoas acometidas pela patologia em questão. A utilizaçáo do protocolo de estresse e compressão ativa contribuiu significativamente para a redução da dor, o ganho de $\mathrm{ADM}$ e a melhora do desempenho ocupacional.

Acredita-se que o trabalho desenvolvido necessite de um envolvimento do paciente que vá além dos atendimentos semanais na clínica. O paciente deve dar continuidade às atividades em seu domicílio, preservando os ganhos a partir de orientaçóes quanto aos exercícios a serem realizados e seus limites, para que não venha a sofrer outras lesôes no membro afetado. 


\section{Referências}

AMATUZZI, M. M. Joelho: Articulaçáo central dos membros inferiores. São Paulo: Roca, 2004.

ANDOLFATO, C.; MARIOTTI, M. C. Avaliação do paciente em hemodiálise por meio da medida canadense de desempenho ocupacional. Revista de Terapia Ocupacional da Universidade de São Paulo, São Paulo, v. 20, n. 1, p. 1-7, 2009.

ARAÚJO, E. W. M. L.; NEVES, S. F. F. Os recursos usados na terapia da mão para a reabilitação de pacientes com Síndrome Dolorosa Regional Complexa do Tipo I. Revista Dor, São Paulo, v. 8, n. 3, p. 1072-1079, 2007.

CHENG, H. M. S. Disabilities of the arm, shoulder, and hand-DASH: Análise da estrutura fatorial da versäo adaptada para o português. 2006. 57 f. Dissertação (Mestrado em Ciências da Reabilitação)-Universidade Federal de Minas Gerais, Belo Horizonte, 2006.

CHOI, Y. S.; LEE, M. G.; LEE, H. M. Epidemiology of complex regional pain syndrome: a retrospective chart review of 150 Korean patients. Journal of Korean Medical Science, Korea, v. 23, n. 5, p. 772-775, 2008.

CORVElO, M. C. et al. Tratamento da distrofia simpático-reflexa no membro superior pelo programa de reabilitação baseado no stresse muscular de tração e compressão ativa. A Folha Médica, Rio de Janeiro, v. 114, n. 2, p. 117-120, 1997.

CURY, V. C. R. et al. Efeitos do uso de órtese na mobilidade funcional de crianças com paralisia cerebral. Revista Brasileira de Fisioterapia, São Carlos, v. 10, n. 1, p. 67-74, 2006.

DAAMEN-DEZOTTI, D. T.; FERRIGNO, I. S. V.; CRUZ, D. M. C. Análise bibliométrica de instrumentos funcionais para avaliaçáo do membro superior em pesquisas. Revista Paraense de Medicina, Belém, v. 25 n. 1, p. 15-22, 2011. Disponível em: <http://files.bvs.br/ upload/S/0101-5907/2011/v25n1/a2584.pdf>. Acesso em: 12 nov. 2014.

DRUMOND, A. S. Exploração do Disabilities Arm, Shoulder and Hand (DASH) através da Classificação Internacional de Funcionalidade, Incapacidade e Saúde (CIF) e da Análise Rasch. 2006. 89 f. Dissertação (Mestrado em Ciências da Reabilitação)-Escola de Educação Física, Fisioterapia e Terapia Ocupacional, Universidade Federal de Minas Gerais - UFMG, Belo Horizonte, 2006.

DZWIERZYNSKI, W. W.; SANGER, J. R. Reflex sympathetic dystrophy. In: BEDNAR, J. M. Hand clinics - complications of common hand procedures. Philadelphia: W. B. Saunders, 1994. p. 29-44.

FERRIGNO, I. S. V. Terapia da Mão: Fundamentos para a prática clínica. São Paulo: Santos Editora, 2007. FONSECA, V. Psicomotricidade: Filogênese, ontogênese e retrogênese. 2. ed. Porto Alegre: Artmed, 1998.
FONSESCA, G. A. Reabilitação da mão. In: LIANZA, S. Medicina da reabilitação. 2. ed. Rio de Janeiro: Guanabara Koogan, 1995. p. 151-168.

FONSECA, M. C. R. et al. Traumas da mão: Estudo retrospectivo. Revista Brasileira de Ortopedia, São Paulo, v. 41, n. 5, p. 181-186, 2006.

FREITAS, P. P. Princípios gerais da reabilitação da mão traumatizada. In: PARDINI, A. G. J. Traumatismos da mão. Rio de Janeiro: Medsi, 2000, p. 381-400.

Freitas, P. P. Reabilitação da mão. São Paulo: Atheneu, 2006.

FUCHS, M.; CASSAPIAN, M. R. A Terapia Ocupacional e a dor crônica em pacientes de Ortopedia e Reumatologia:revisão bibliográfica. Cadernos de Terapia Ocupacional da UFSCar, Sáo Carlos, v. 20, n. 1, p. 107-119, 2012.

GALER, B. S.; DWORKIN, R. H. Complex regional pain syndromes. A clinical guide to neuropathic pain. Minneapolis: McGraw-Hill, 2001.

LAURETTI, G. R.; VELOSO, F. S.; MATTOS, A. L. Reabilitação funcional e analgesia com uso de toxina botulínica Ana Síndrome Dolorosa Regional Complexa Tipo I do membro superior. Relato de Casos. Revista Brasileira de Anestesiologia, Botafogo, v. 55, n. 2, p. 207-211, 2005.

MAGALHÃES, L. C.; MAGALHÃES, L. V.; CARDOSO, A. A. Apresentação. In: LAW, M. et al. Medida Canadense de Desempenho Ocupacional (COPM). MAGALHÃES, L. C.; MAGALHÃES, L. V.; CARDOSO, A. A. (Orgs.). Belo Horizonte: Editora UFMG, 2009. p. 9-13.

MORRIN, J. B.; DAVEY, V.; CONOLLY, W. B. A Mão: Bases da terapia. Barueri: Manole, 2001.

MULLINS, P. A. Reflex sympathetic dystrophy. In: STANLEY B. G.; TRIBUZY, S. M. Concepts in hand reabillitation. Philadelphia: F. A. Company, 1992.

MRUS, J. M. et al. Utilities derived from visual analog scale scores in patients with HIV/AIDS. Médical Decision Making, Philadelphia, v. 23, n. 5, p. 414-421, 2003. http://dx.doi.org/10.1177/0272989X03256884

ROCHA, C. E. D. Melhora da qualidade de vida de pacientes com dor neuropática utilizando de monitorização ambulatorial contínua. Revista Dor, São Paulo, v. 12, n. 4, p. 291-296, 2011.

SALTER, M.; CHEEHIRE, L. Hand therapy: Principles and practice. 1st ed. Oxford: Butterworth- Heinemann, 2000.

SAMPAIO, R. F. et al. Aplicação da Classificação Internacional de Funcionalidade, Incapacidade e Saúde (CIF) na prática clínica do fisioterapeuta. Revista Brasileira de Fisioterapia, São Carlos, v. 9, n. 2, p. 129-136, 2005. 
TEIXEIRA, M. J. et al. Epidemiologia clínica da dor músculo-esquelética. Revista de Medicina, São Paulo, v. 80, n.1, p. 1-21, 2001. Ediçáo especial, parte 1.

WALSH, M. T. Therapist's management of reflex sympathetic dystrophy. In: HUNTER, L. Reabilitation of the hand: Surgery and therapy. 4th ed. St. Louis: Mosby, 1995. p. 1617-1629.
WATSON, H. K.; CARLOSON, L. Treatment of reflex sympathetic dystrophy of the hand with an active stress loading program. The Journal of Hand Surgery, St. Louis, v. 12, n. 1, p. 779-85, 1987.

ZAKKA, T. R. M. et al. Síndrome complexa de dor regional e gestação. Relato de caso. Revista Dor, São Paulo, v. 12, n. 1, p. 74-7, 2011.

\section{Contribuição dos Autores}

Aline Sarturi Ponte : concepção do texto, organização de fontes e/ou análises, redação do texto. Barbara Santos Luccas Duarte, Maria Celoni de Mello de Godoy e Thais Rosa Costa: organização de fontes. Miriam Cabrera Corvelo Delboni: Orientadora, organização de fontes e/ou análises, redação do texto, revisão. 